\title{
Philosophical commitments, empirical evidence, and theoretical psychology
}

Theory \& Psychology 20I5, Vol. 25(I) 3-24

(C) The Author(s) 2014

Reprints and permissions:

sagepub.co.uk/journalsPermissions.nav DOI: $10.1|77 / 09593543| 4563324$

tap.sagepub.com

\author{
Pamela M. Allen
}

Oregon State University

\section{Sharyn Clough}

Oregon State University

\begin{abstract}
The philosophical or theoretical commitments informing psychological research are sometimes characterized, even by theoretical psychologists themselves, as nonempirical, outside the bounds of methodological consideration, and/or nonrational. We argue that this characterization is incoherent. We illustrate our concern by analogy with problematic appeals to Kuhn's work that have been influential in theoretical psychology. Following the contemporary pragmatist tradition, we argue that our philosophical/theoretical commitments are part of our larger webs of belief, and that for any of these beliefs to have meaning their content must be informed by our practical engagement with the world, i.e., they are based on empirical evidence, broadly construed. It is this empirical basis that allows us to recognize our commitments at all and rationally to assess and criticize them when necessary. We conclude by demonstrating a rational assessment of the philosophical/theoretical commitments underlying a recent study in the social psychology of religion.
\end{abstract}

\section{Keywords}

holism, Kuhn, philosophy of science, pragmatism, social psychology

We focus critical attention on instances in the theoretical psychology literature where the philosophical or theoretical commitments accompanying psychological research are characterized as worldviews, as nonempirical, and/or nonrational, as existing outside the

\section{Corresponding author:}

Sharyn Clough, School of History, Philosophy, and Religion, Oregon State University, 322 Milam Hall, Corvallis, OR 9733I, USA.

Email: sharyn.clough@oregonstate.edu 
bounds of methodological consideration (e.g., Sarason, 1984; Vandenberg, 2010; Wertheimer, 1986). We argue that this characterization is incoherent. We illustrate our concern by analogy with problematic appeals to Kuhn's work that have been influential in theoretical psychology (e.g., Gergen, 1985; Manicas \& Secord, 1983).

We then sketch an argument for our positive claim, namely that philosophical/theoretical commitments can themselves be articulated in terms of their connection to empirical (though not necessarily experimental) evidence. In line with a diverse body of social scientists highlighting the importance of American pragmatism (e.g., Brinkmann, 2008, 2011; Martin, 2003; Morgan, 2007), we focus especially on the contemporary pragmatist approach of Quine and Davidson. For Davidson, in particular, all our commitments, our beliefs - be they evaluative, descriptive, or otherwise - are part of a semantic continuum, or a web of belief, that links the abstract and theoretical to the concrete and observable. Insofar as any of these beliefs have any meaning, their semantic content must be informed more or less strongly by our practical engagement with each other and the world, that is, these beliefs must be informed by experiential, empirical evidence, broadly construed (e.g., Davidson, 1995/2004). Insofar as our philosophical/theoretical commitments are beliefs that have meaning, and we take this as uncontroversial, then they too arise from an engaged relationship with empirical evidence. It is this relationship with empirical evidence that allows us to recognize our commitments at all, and allows us rationally and critically to assess their strength. The differences between beliefs we identify as philosophical, theoretical, and abstract, on the one hand, and descriptive, concrete, and observable, on the other, are not differences between beliefs that are informed by empirical experience and those that are not. Rather the differences are functional and context specific, a pragmatist point made by Dewey (1916) and, the later Wittgenstein (1953/2001).

In keeping with our pragmatist orientation, we conclude by showing what a rational assessment of philosophical and theoretical commitments in psychology looks like in practice. In particular, we offer a critical examination of the philosophical and theoretical commitments underlying a recent study in the social psychology of religion.

\section{Philosophical/theoretical commitments as nonempirical}

We begin with a fairly recent case in theoretical psychology, namely Vandenberg (2010). Vandenberg uses the history of hypnosis research as a case study to illustrate the role of philosophical commitments in psychology more generally. He begins by stating, "Not all disputes in psychological science are empirical matters - many entail philosophical entanglements and confusions" (p. 51). Vandenberg concludes his essay by noting that "philosophical analysis is as important as methodological rigor" (p. 63). While we applaud his conclusion, we are unsure how Vandenberg imagines philosophical analysis should proceed, if not guided by methodological rigor and appeal to empirical matters. It might be that Vandenberg is eliding a methodological examination of empirical evidence generally, with the assessment of evidence provided by formal experiments. This common conflation is particularly troublesome for psychologists who, for a variety of practical reasons, are not often able to perform experiments in the strict sense, but who nonetheless rationally and rigorously gather and analyze empirical evidence from quasi experiments, statistical modeling, case studies, and natural settings. Holding up formal 
experimental design as synonymous with rational, methodological assessment of empirical evidence is misleading and unnecessarily reductive. Practical restrictions having to do with scale, for example, similarly restrict the experimental designs used in many other sciences such as geology, evolutionary biology, and astronomy. What remains rational, critical, and methodologically rigorous in these kinds of scientific investigations is the nondogmatic weighing of the relevant and representative sets of experience taken as evidence for or against a hypothesis.

In what follows, we argue that the philosophical/theoretical commitments informing psychological research are susceptible to a similarly rational, methodological approach employing critical, empirical analysis, broadly construed. We acknowledge that these commitments are not always placed under this kind of rational, critical scrutiny (which, we take it, is part of Vandenberg's point), however we think they are at least capable of being so placed, or as capable as are any other sets of beliefs, and it is their empirical content that allows for this scrutiny. ${ }^{1}$ We take ourselves to be consistent here with Osbeck's (2005) helpful analysis of the role of method or rationality in psychology. Osbeck argues that psychologists too often accept a forced choice between embracing a problematic idea of method as a universal, formalist "set of rules assigned in advance," or rejecting method altogether; the latter often in a misguided appeal to Feyerabend's Against Method (1975), understood as promoting the idea that "anything goes" (Osbeck, 2005 , p. 10). Osbeck argues that the proper focus of critical attention for psychologists should be the simplistic equation of method or rationality with rule following. Psychologists should not reject rationality and method per se, but instead embrace a "revisioning" of rationality understood as more humane, less mechanical, and drawing from a more diverse set of philosophical perspectives (p. 24). Similarly the sense of "empirical, rational analysis" we prescribe here cannot be reduced to "formal experimentation," but mirrors the characterization we gave earlier of the kinds of hypothesis testing that occur in any number of nonexperimental science settings, namely, the nondogmatic weighing of the relevant and representative sets of experience taken as evidence for or against any given philosophical or theoretical commitment. As we model in the final section of our paper, part of what we think should count as relevant and representative evidence here concerns the experience we have as researchers regarding the consequences that our various commitments bring. Indeed that we can even recognize these commitments as commitments comes from identifying their consequences in psychological research. We advocate for a more explicit recognition of this process.

\section{Kuhn, paradigms, and rationality}

Our concerns with the characterization of philosophical/theoretical commitments as nonempirical, outside the bounds of methodological consideration, and/or nonrational is further illustrated by analogy with problematic appeals to Kuhn's work found in some influential essays in theoretical psychology (e.g., Gergen, 1985; Manicas \& Secord, 1983).

By way of a brief review of the relevant features of Kuhn's work, recall that in The Structure of Scientific Revolutions (1962/1996) Kuhn argued that the earliest proponents of Copernican astronomy could not have come "on board" as it were, as a result of any experimental evidence refuting the Ptolemaic view. No such evidence was available to 
them. Indeed, not even the later work of Kepler, nor Galileo, provided experimental evidence against Ptolemy's geocentric theory. The scientific ideal that theory-choice proceeds in terms of direct empirical evidence produced by "crucial experiments," is largely, Kuhn argued, an artifact of the ahistorical nature of science textbooks and pedagogy (Kuhn, 1977, p. 327; Kuhn, 1962/1996, ch. 11). These idealized empirical conditions are just that, idealizations - they seldom obtain in practice when scientists make decisions between competing scientific theories. In the case of the Copernican revolution, Kuhn inferred that, in the absence of a clear experimental refutation of the Ptolemaic system, early supporters of the new Copernican paradigm were likely attracted by broader philosophical commitments aligned with the paradigm. Kuhn referenced Kepler's commitments to Neoplatonism and the Hermetic movement as likely reasons for Kepler's support of the Copernican system (Kuhn, 1977, p. 325).

Readers of this journal are familiar with what happened next. When Kuhn emphasized the role of scientists' allegiance to paradigms, over and against any appeals to direct empirical evidence of the sort provided by crucial experiments, many critics argued that he had mischaracterized how scientists make decisions between competing theories; that he was dismissing the role of empirical evidence, method, and/or rationality altogether. Kuhn spent the rest of his career responding to these kinds of misreadings of his work.

To be fair to his critics, Kuhn's early discussion of paradigms was, and is wellacknowledged to be, ambiguous, and included for example, viewing paradigms as exemplars of good science, as worldviews, as epistemological stances, and/or as disciplinary matrices of shared philosophical and theoretical commitments among a group (see Morgan, 2007 for a review). Commentators of the mature Kuhn continue to debate the issue, but there is some consensus on viewing paradigms as a mix of these, specifically as disciplinary matrices that are focused around the detection of resemblance relations to exemplars of good science (e.g., Barker, Chen, \& Andersen, 2003; Bird, 2000). However, regardless of which definition of paradigms is used, some critics of Kuhn (and, as we'll see, even some supporters) have characterized paradigms in terms of a presumed common distance from questions of empirical evidence, and an identity with the nonrational or irrational (Kuhn, 1977).

We focus on those instances in theoretical psychology when Kuhnian paradigms have been viewed as disciplinary matrices of philosophical and theoretical commitments, along with the requisite understanding of these commitments as separate from empirical examination, and identical with the irrational. In their influential essay "Implications for Psychology of the New Philosophy of Science," Manicas and Secord (1983) discuss and dismiss the "Kuhnian or paradigmatic critique" of the standard positivist view of science, arguing that if we accept an account of science, including psychology, as being bound by philosophical and theoretical commitments that make up a paradigm, then we admit that we have no theory-neutral foundation of observations on which to build, and we end up "courting irrationalism" (p. 401). In Gergen's now classic essay "The Social Constructionist Movement in Modern Psychology" (1985), he too offers this characterization of Kuhnian paradigms as a set of philosophical/theoretical commitments that undermine scientific appeals to empirical evidence, but unlike Manicas and Secord, Gergen welcomes the characterization. According to Gergen, the Kuhnian critique of a strict theory/observation 
split, that is, the view that our theoretical categories ineliminably affect our observations, shows that we need to "suspend belief that commonly accepted categories or understandings receive their warrant through observation" (p. 267) and that justification in psychology, and science more generally, can no longer be naively seen as the outcome of empirical methodology (p. 273). Gergen's work has been influential in a variety of debates in the theoretical psychology literature involving worries about what the (inevitable) role of the conceptual, theoretical, and/or the philosophical means for the rationality and legitimacy of psychological research (see Stam, 2001, for a review of this debate and these worries).

We highlight the view of paradigms as a disciplinary matrix of shared philosophical/ theoretical commitments because, while it does not capture the contemporary, consensus view among Kuhn scholars that focuses on the paradigmatic role of exemplars in science, it is a view of paradigms that has been influential in the theoretical psychology literature, and it seems analogous to the nonempirical, nonrational view of philosophical/ theoretical commitments found more broadly in this literature, and on which we want to focus our critical gaze. Morgan's discussion of paradigms is useful in this context (Morgan, 2007). He explains that a paradigm on the conception we are interested in refers to "systems of beliefs and practices that influence how researchers select both the questions they study and methods they use to study them" (p. 49). These systems of beliefs and practices include the shared set of philosophical/theoretical commitments that must be taken for granted; that is, background assumptions that bind and organize a research program to allow for, for example, the identification of and response to errors in the results (e.g., Kuhn, 1970). If there are no paradigmatic assumptions of this kind guiding the research, then any anomalous results are uninterpretable-we cannot recognize them as errors and learn from them (Kuhn, 1970, p. 22).

In "Objectivity, Value Judgment, and Theory Choice," Kuhn himself argues that these kinds of paradigmatic assumptions need not be divorced from rational assessment (1977). ${ }^{2}$ He begins by acknowledging the role of criteria for theory choice in science that he and most others would consider to be non-controversially "objective" and "rational" (in his essay, Kuhn uses these two terms interchangeably). That is, to be acceptable to a scientific community, the results of research need to be accurate, consistent, broad in scope, simple, and/or fruitful (he notes that this list is not exhaustive, but in what follows we will focus on these five criteria). Kuhn reminds us, however, that while the use of these criteria can proceed rationally, the criteria themselves are imprecise and often conflict with each other (1977, p. 322). By themselves they do not always unambiguously favor one theory over another. However, he also argues that objective criteria such as (empirical) accuracy can still function broadly as values or norms that guide the holding of any belief, even when, in the absence of specific experimental results that unambiguously support one belief over another, we cannot use empirical accuracy as a straightforward decision procedure or rule (1977, p. 331).

In cases when a scientist compares her research with that produced by scientists working with different sets of philosophical/theoretical assumptions about, say, what sorts of questions are worth asking, and what sorts of data count as evidence, the five criteria cease to be useful for deciding between specific experimental results, and must instead be applied to the philosophical/theoretical commitments themselves. Kuhn 
mentions that a scientist, still guided by these five criteria, may extend their range of application beyond the immediate experimental setting in question, and appeal, for example, to her previous experience as a scientist more broadly. Her experiences can be thought of as subjective, in that they are confined to or arise from the life of an individual, but they can still be appealed to in a rational process of decision-making (Kuhn, 1977, pp. 325, 336).

Similarly, we argue that, in the case of appeals to philosophical/theoretical commitments that lie, strictly speaking, beyond the experimental findings in support of any given research project, these commitments can still be rationally assessed. Commitments of a more philosophical or theoretical nature, if they are to make any sense at all, must themselves fall on the same continuum as, for example, commitments arising from the results of experimental research. In all of these cases, these commitments function as criteria for theory choice by appealing to the empirical world, broadly construed.

Placing these Kuhnian arguments in the terms of psychological research, we argue that the existence of differences in philosophical/theoretical commitments does not preclude the possibility of critical rational discussion about those commitments. Stated positively: such discussion can appeal rationally to the connections between beliefs about philosophical/theoretical commitments and beliefs about the available empirical evidence. As with any appeal, the choices arrived at are contingent, and arise from complex engagement with the world and our fellow researchers. This element of our view chimes with Sternberg, Gigorenko, and Kalmar's (2001) essay on "theory knitting."

In sum, we think it important to reject the claim, popularly attributed to Kuhn, that scientists working with conflicting philosophical/theoretical commitments are unable in principle to rationally assess each other's work. While there are debates about the ability to identify errors across paradigms, and about Kuhn's notion of incommensurability more generally, ${ }^{3}$ we are persuaded by his arguments in the "Objectivity" essay that scientists working with different philosophical/theoretical commitments can work to translate each other's claims, and can appeal to shared rational norms of empirical accuracy, for example, to make their case (Kuhn, 1977, p. 339). To be sure, he rejects the idea that there are a priori, theory-neutral facts of the matter that will guarantee one outcome, rather than another. But this rejection is eminently reasonable. To believe that we need a guarantee of this sort to underwrite progress in psychology, or any other science, is to hold on to a perverse and incoherent notion of how even the "hardest" of sciences actually work (to borrow the sexually loaded analysis employed by Meehl, 1978).

As Morgan (2007) notes, in Kuhn's Postscript to the third edition of The Structure of Scientific Revolutions (Kuhn, 1962/1996), Kuhn acknowledges that there are bound to be degrees of "communication breakdown" between holders of different background assumptions (Morgan, 2007, p. 58), rather than complete incommensurability. If conflicting scientific results emanate from completely disparate philosophical/theoretical commitments, then critical discussion about those results will be difficult (Kuhn, 1977, p. 338). But one must begin by trying. Trying requires acknowledging that there are philosophical/theoretical commitments at play, and spending some time holding these up to the same kinds of critical empirical scrutiny with which we analyze the results of experimental methods. 


\section{Pragmatism and semantic holism}

Let us say, then, with Kuhn, and the theoretical psychologists whose work we've discussed, that major historical shifts in science are not always, or even typically a result of experimental evidence for a new theory, as against an older theory, but are instead the result of a shift in paradigmatic commitment, here defined as a shift in shared philosophi$\mathrm{cal} /$ theoretical commitments with a host of practical consequences, including what sorts of questions are worth asking, what sorts of data can count as evidence, and what sorts of results are recognized as errors (Kuhn, 1962/1996; Vandenberg, 2010, p. 51). As Vandenberg puts it: "Empirical [experimental] evidence is but one facet in the advancement of psychological science for, indeed, the very ground of what constitutes legitimate scientific evidence continues to shift" (p. 51). It does not follow that a shift in attention away from direct experimental evidence and toward philosophical/theoretical commitments about what counts as evidence must itself be a shift away from empirical examination and toward irrationality. Indeed, as we argue below, it is not even clear how we could coherently use language to talk about such a shift.

Within the American pragmatist tradition, observations of language acquisition have been used to argue that the acquisition of any of our commitments, whether they be theoretical, philosophical, or more straightforwardly empirical, arises from practical and public engagement with other language users and the shared empirical world about which we are communicating (e.g., Davidson, 1989; Dewey, 1929, esp. ch. 9; Quine, 1960). It is this practical engagement with each other and the world that gives any and all of our beliefs their meaning, their semantic content. There is no principled, substantive difference in the acquisition process by which we form beliefs concerning the empirical results of experimental manipulation, and beliefs concerning the results of philosophical or theoretical deliberation (Clough, 2008, 2011; Davidson, 1995/2004).

For any and all of our beliefs to have meaning, they must have empirical content and/ or they must be semantically linked to beliefs that do. This semantic holism reminds us that the empirical content of philosophical or theoretical commitments is as available for rational evaluation as any other kind of commitment. To make use of Quine's web metaphor, all of our commitments must be part of the same holistic web of belief. It is their placement in our webs of belief that provides us with the semantic content that we appeal to when we rationally deliberate between differing commitments. This rational deliberation involves assessing which commitments are better connected to other commitments we believe to be well-supported through practical engagement with the consequences of those commitments.

The semantic holism prescribed by Kuhn is very similar to the pragmatist view we support. In The Structure of Scientific Revolutions, Kuhn argued that the linking of any one belief with others in the conceptual/paradigmatic web meant that changes in the meaning of one would affect many (Kuhn, 1962/1996, ch. 12). For scientists whose conceptual/paradigmatic webs have shifted relative to a change in philosophical or theoretical commitments, this holistic relationship would constrain the ease with which they could understand the work of scientists whose webs have not shifted in the same way; including constraining what counts as an anomaly or an error. If Davidson and the pragmatist view we support is right though, the constraints cannot be complete and errors can 
be evaluated across paradigms (e.g., Davidson, 1995/2004; Mayo, 1996); though clearly any evaluation of errors is made more difficult by having, first, to acknowledge the role of any given paradigm, that is, any given set of philosophical and theoretical commitments, in defining which errors get recognized at all.

It is worth highlighting some contrasts between our pragmatist approach and a positivist or empiricist philosophical approach that makes similar-sounding claims about the importance of empirical evidence. For example, we are not advocating a return to the verificationism associated with positivism, whereby theoretical statements are judged meaningful only if they can be linked objectively through a series of correspondence rules to empirical observations about the world. The pragmatism we reference here is more holistic than that, acknowledging a continuum of interconnected webs of beliefs, rather than splitting the two into ontologically separate spheres (the empirical/observational and the theoretical/nonobservational) that need epistemic linking (Clough, 2003, ch. 6).

Additionally, there is no need to make the empiricist claim that beliefs about empirical observations are epistemically foundational because they are somehow theory neutral. Our pragmatist view is consistent with claims that more straightforwardly empirical beliefs are theory laden, that is, laden with/by their web-like connection to philosophical or theoretical beliefs. But the holistic view we support has theoretical beliefs laden by more straightforwardly observational beliefs as much as the reverse. And again, the model of belief webs explains the acquisition of any of our beliefs, from the observational to the theoretical, through our empirical, practical engagement with and in the world of which we are a part.

Of course, not all engagements produce equally accurate beliefs and commitmentswhether they be abstract, theoretical, and philosophical, or concrete, observational, and experimental - it is the practical, empirical engagement producing any and all of these commitments that allows us rationally, and critically, to evaluate their strength. This pragmatist approach is in line with the work of a number of social scientists (e.g., Brinkmann, 2008, 2011; Martin, 2003; Morgan, 2007). In particular, our project parallels Morgan's (2007) prescription of pragmatism, not only as a way of articulating the continuum on which philosophical and more straightforwardly empirical commitments lie, but as a way of describing a new kind of paradigm for social science research more generally. Morgan advocates for what Dewey called "inquiries" in social science as in everyday life - that is, the rational, critical analyses "which we undertake to assess either the workability of any potential line of action, or the bases for what we claim as warranted assertions" (Morgan, 2007, p. 66). In this application of the pragmatist approach, lines of action correspond to decisions and behavior in the process of carrying out research, warranted assertions correspond to the theoretical/philosophical commitments of the researcher, and workability constitutes the consequences that follow from the way the research was conducted.

In contrast, Vandenberg (2010) invokes precisely the sort of split between philosophical commitments and empirical evidence to which we draw critical attention. He includes a discussion of construct validity as a prime example of the sorts of shifts in philosophical and theoretical commitment that affected the history of hypnosis research. Setting aside debates about the accuracy of the historical details he provides, note the language used and the widely shared presumption that philosophical/theoretical issues are importantly 
separate from empirical issues. He portrays the shift in commitments regarding the construct validity of hypnosis as "quiet," because, on his account, the shift occurred in an unquestioned, unacknowledged, and therefore unreasoned or irrational fashion. That this irrational shift was philosophical and theoretical in nature becomes clear when he contrasts it with the "empirical skirmishes" in which hypnosis researchers were involved. More specifically, he claims that hypnosis researchers were working under the assumption that the only important features on which to focus were empirical (by which he means experimental), and they (and Vandenberg) believe empirical issues to be separate from the philosophical issues on which they should have been focusing (p. 61). In Vandenberg's view, the problem was that this exclusive focus on questions of empirical evidence allowed the answers to important philosophical questions to shift without the benefit of critical scrutiny. Again, leaving aside the accuracy of the historical details, we think it makes more sense to describe the problem as one where some shifts in commitments were properly subjected to critical, empirical scrutiny (those related to experimental results), and some (those philosophical commitments) could and should have been so subjected but were not. Both kinds of commitments are capable of being empirically evaluated in a critical, rational way.

Indeed, when it comes to the issue of construct validity more generally, Vandenberg applauds the rationality of Meehl's philosophical contributions (e.g., Cronbach \& Meehl, 1955, cited in Vandenberg, 2010, p. 55). Vandenberg also models a rational, critical analysis of philosophical commitments when he describes MacCorquodale and Meehl's (1948) influential work on theoretical constructs. Here Vandenberg writes in support of MacCorquodale and Meehl's arguments against behaviorist philosophical commitments, agreeing with them that "inference from data to theory can [emphasis added] be scientifically defensible" and that the validation of philosophical, ontological claims about theoretical constructs "involves evaluating the force of evidence supporting an underlying construct" (Vandenberg, 2010, p. 55).

We agree and argue that philosophical positions regarding, for example, the ontological status of theoretical constructs, are arrived at and can be adjusted in the face of empirical experience, generally, or in the face of more formal experimental evidence, in particular. One mark of irresponsible science is the failure to adjust commitments in the face of evidence conflicting with those commitments. The mark of a responsible scientific approach is the refusal to hold philosophical (or any other kind of) commitments dogmatically (Anderson, 2004). The empirical soundness of any particular commitment must be capable of being doubted, though as Davidson argues, not all or even most can be up for grabs at once (Davidson, 1974/1984, pp. 196-197). In any given scientific project, the empirical soundness of a number of commitments must be assumed, in order for even the most basic of hypothesis testing to get off the ground. Depending on how formally these taken-for-granted commitments are organized and shared, we might want to call them "paradigmatic."

While these commitments are capable of rational assessment, they must be brought to light for the assessment to be possible - their "taken-for-grantedness" must be noticed. One can certainly find examples in the history of science where (a) commitments so noticed are then analyzed (anew) empirically, and found to be wanting, but (b) the scientists involved held on to those commitments anyway. In these moments, problems of 
scientific integrity may arise. However, when they do arise, the problem results from the dogmatism with which the commitments are being held, and not from the commitments being philosophical or nonempirical.

Henley's (1989) discussion of paradigms is illustrative. In his analysis of Meehl's classic essay "Theoretical Risks and Tabular Asterisks" (Meehl, 1978), Henley characterizes Meehl's arguments as arising from between psychological paradigms - a situation that Henley uses to explain why Meehl's paper, though oft-cited, has not been given sufficient uptake in psychology. According to Henley's reading of Kuhn, arguments that arise between paradigms, like those of Meehl, are "not heard" by those working within different paradigms, due primarily, explains Henley, to the fact that members of different paradigms have incommensurate psychological/social/political commitments. While this might be an apt explanation for the failure of Meehl's paper to get critical uptake, Henley's is not an argument against the possibility of rational, critical analysis of the different commitments held by members of different paradigms.

Indeed, Vandenberg concludes his paper by calling for just this kind of rational, critical deliberation regarding the philosophical underpinnings of psychological research. We argue that such rational deliberation about our commitments is incoherent without some understanding of the empirical nature of any commitment, philosophical, theoretical, or otherwise. This is the empirical, pragmatic approach to our philosophical/theoretical commitments that we take in the final section of our paper, where we examine the paradigmatic, that is shared, taken-for-granted, philosophical/theoretical commitments underlying a recent study in the social psychology of religion. ${ }^{4}$

We should note here that while we earlier flagged a criticism of Wertheimer's (1986) conceptualization of worldviews as nonrational, we want to acknowledge that it is otherwise a very good articulation and critical evaluation of some of the basic, philosophical/ theoretical commitments at play in social psychological research. Our concern with Wertheimer's presentation remains that, like Vandenberg, Wertheimer conceives of these philosophical commitments in terms of worldviews that are nonrational, so it is hard to see on what he thinks his critical evaluation is based. Regardless, his attempt to make explicit that which is usually unspoken is apt, and we model it below.

\section{Philosophical/theoretical commitments guiding social psychology of religion}

We have argued throughout this paper that philosophical/theoretical commitments are just as amenable as any other kind of beliefs to the nondogmatic weighing of the relevant, and representative sets of experience taken as evidence for or against them. And as pragmatists, part of what we think should count as relevant and representative evidence here, concerns the experience we have as researchers regarding the consequences that our various commitments bring. Indeed that we can even recognize these commitments as commitments comes from identifying their consequences in psychological research.

To support this claim we now critically examine the philosophical/theoretical commitments that guided our recent social psychological attempts to operationalize and test Buddhist claims about the (local) effects of karma. 


\section{Testing karma}

In accordance with De Silva (1990) we think that Buddhist theories of mind offer testable propositions, and these can be fruitfully linked with psychological theories of social cognition in the academic north/west. For example, Buddhist theories of karma and psychological theories of social cognition both propose that when people behave in cooperative ways, they tend to interpret future events in more pro-social ways than they would otherwise (Bruner, 1957; Tsongkhapa, 2000).

We used a social psychological experimental paradigm and quantitative statistical methods to test one aspect of karma well-agreed on across a number of Buddhist traditions: the karmic prediction that cooperative, pro-social action leads people to interpret the behavior of others as similarly cooperative and pro-social. The study focused on the Tibetan Buddhist tradition, which divides karma into three phases: the will to act that precedes the act (i.e., will or volition); the act itself; and the impression that is left on the mind after the first two phases have passed (Dargyay, 1986, p. 170). This impression or "seed" lies dormant until the appropriate conditions encourage it to grow into a concordant result. It then becomes further rooted or entrenched, and the cycle continues, consistent with the Buddhist theory of mind that past behavior "trains" us to perceive the world in a way consistent with that behavior (Tsongkhapa, 2000). For Buddhists, karma and reincarnation are interlinked, though not necessarily so. Reincarnation is related to the claim that karmic effects do not always come to full fruition within a single human life, but may continue to exert causal influences in the next life. Obviously, this makes definitive falsification of karmic phenomenon difficult, though no more so than for any number of sufficiently complex psychological phenomenon, a point we return to below. ${ }^{5}$

Participants first completed several measures of their pre-existing beliefs about levels of trustworthiness in other people. They were then randomly assigned to one of three conditions where they read a paragraph endorsing a certain "life philosophy," especially as it applies to economic rationality. Two of the conditions involved priming tasks in which participants read paragraphs focused either on "the golden rule" (using words relating to helping and selflessness) or on a contrasting "self-serving" philosophy of economic rationality (using words relating to competition and selfishness). A third condition contained a paragraph with "neutral" content.

Next, half of the participants proceeded to play an adapted version of a standard single-round prisoner's dilemma (PD) game and the other half were assigned to a "nogame" control condition. The PD game involved a hypothetical business scenario in which choosing to cooperate (not selling a newly introduced product) is risky but if both players cooperate, they gain the largest possible shared profit (Figure 1). Selling the new product is the strategy that maximizes one's own personal profit. Therefore the game gave participants the opportunity to act in either a cooperative or a competitive way and simulated behavior of moral consequence. Participants were told that after they played the game, their responses would be compared to the other player's response to determine the (hypothetical) outcome.

We expected that those primed with the "golden rule" and "self-serving" philosophies would cooperate or compete in the game, respectively. The influence of the prime on PD 


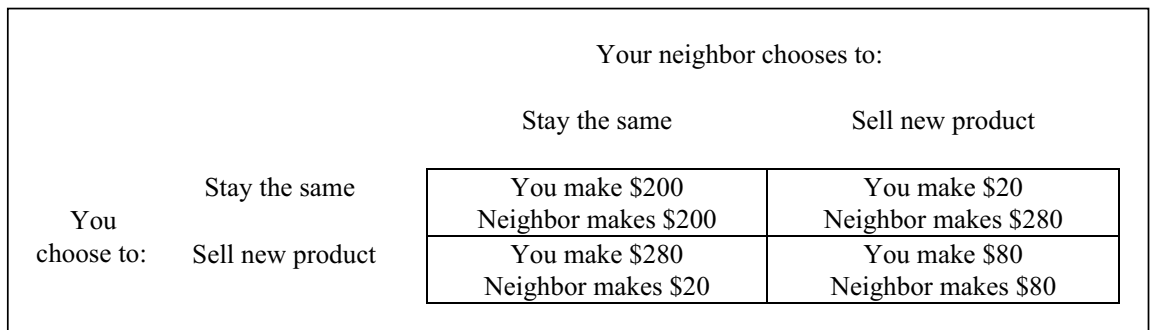

Figure I. Prisoner's dilemma payoff matrix used in the experiment.

behavior was our manipulation of the independent variable and was meant to model the second level of karmic action - the planting of cooperative karmic seeds.

The third level of karmic action, the impression that is left on the mind after an action, was tested after the completion of the PD game in the form of a questionnaire designed to assess mood, followed by an impression formation task. The latter was a disambiguation task, a common method for showing the effects of an activated concept on perception of other people (Bargh, Bond, Lombardi, \& Tota, 1986). In the disambiguation task, the participants read a paragraph about the actions of a fictional person, Roy, which were previously shown in a pilot test to be ambiguous in terms of whether he was acting cooperatively or acting like a pushover. Using a 10-point scale, participants rated their impressions of Roy on a variety of dimensions including how cooperative or susceptible to manipulation he seemed to be. This impression formation rating was the primary dependent variable of interest.

The experiment had a $3 \times 2$ design ("reading the 'golden rule' paragraph" vs. "reading the 'self-serving' paragraph" vs. "reading the "neutral' paragraph," on the one hand, by "playing the PD game" vs. "not playing," on the other). Participants who played the PD game and, based on their reading of the paragraph, had acted in a pro-social manner in the PD game, were expected to see the behavior of the ambiguous target as more cooperative than did participants who acted competitively in the PD game. Based on previous social cognition research, the no-PD game control group participants who read the "golden rule" paragraph were expected to perceive Roy as more cooperative than did the control group participants who read the "self-serving" paragraph. However, referencing the three-phase nature of karmic action, it was predicted that the results for the no-game participants should have been weaker than those for the game-playing participants who were given an opportunity to act in a cooperative or competitive way. In addition, the neutral-paragraph control participants who played the PD game and chose cooperative versus competitive actions should have also shown differences in how they rated Roy, but these differences should have been smaller than those for the people who received the prime.

\section{Making our commitments explicit}

Our work was guided by a number of philosophical or theoretical commitments that are paradigmatic in the sense that they governed our choices of experimental design, method, and analysis of evidence, and are typically taken for granted, entrenched, and formally 
organized in social psychological research in the northern/western academic context. In order to rationally assess the evidence for our commitments we need to be explicit about them. This is easier said than done. Some of the commitments we identify will seem obvious to readers of this journal, others less so. One major commitment was that the phenomenon of karma had empirical consequences that could be measured in real time. Buddhist theories of mind support this commitment insofar as the major tenets of the tradition, such as the causal nature of karma, are viewed as testable hypotheses, rather than as matters requiring dogmatic adherence. Of course there are different kinds of "testing" and some kinds are more formal than others. Our pragmatist approach recognizes that these different kinds of testing exist on a continuum. As scientists in the northern/western academic context push against the formal end of the testing continuum, we gain accuracy at the expense of relevance or ecological validity. We erred on the side of accuracy.

The worry about relevance is intimately related to the pressure placed on another of our commitments, namely our commitment to operationalizing our definitions. We assumed it was possible to bring karma into a controlled, artificial environment by creating an operational definition that would adequately capture the essence of the phenomenon. And, if control over the environment were thorough enough, it would be possible to demonstrate a causal relationship between the independent and dependent variables through inferential statistics that rely on dichotomous significance testing. Many Buddhist schools reject the idea that recognizing karma requires knowledge of (and therefore the existence of) past lives, and we took this rejection for granted. A related commitment was that an operational definition at the level of the whole person (as opposed to groups, or processes within an individual) was the appropriate level at which to capture the phenomena.

Individuating commitments is difficult and there are many possible ways to enumerate our commitments. Although we focus on those listed above in our discussion, several more are identified as governing our choices. Participants were assumed to be naïve and passive in the research process; measuring five related constructs, interpersonal trust, philosophy of human nature, mood, etc., was adequate to account for the range of possible alternative influences on participants' PD behavior and impression ratings. Also, once those controls were in place, no other factors would be relevant.

We acknowledge that insofar as the commitments converging to guide the karma study can be identified as paradigmatic, they came from paradigms defined at different levels. Our study was guided by the commitments of the broad methodological paradigm shared within academic psychology as a whole (e.g., operationism and significance testing) and the unique paradigms within psychology involving the specific commitments of experimental social psychologists (e.g., control over ecological validity) and commitments of psychologists of religion (e.g., that operational definitions of spiritual phenomena are adequate). While some of these commitments likely produce more dissension than others within psychology generally, none of them are immune from criticism, and, once made explicit, the evidence in their support is available for empirical assessment, broadly construed. In this section we model a rational, critical analysis of the evidence for these commitments.

\section{Analyzing the evidence}

Some of these commitments are identified by theoretical psychologists as arising from a positivistic philosophical paradigm which is taken as evidence against their use (e.g., 
Bickhard, 1992). For example, the use of operational definitions is often criticized for its relation to positivism (Koch, 1992; Rogers, 1989; Sugarman, 1995). While we earlier distanced our pragmatist position from some elements of positivism, the details matter. We find no straightforward evidence showing that operationism by itself is problematic. ${ }^{6}$ In practice, an operational definition may not be more than "an explicit methodological description of how something is measured" (Rogers, 1989, pp. 147, 150), meant to connect theory and observation consistently across differing experimental designs (Slaney, 2001). In our study, there were a number of layers of operations meant to measure karma. In the PD game, we used the choice of not selling the new product as a measure of cooperative behavior, and we used that cooperative behavior to measure causal behavior of moral import.

The commitment to operationism can become problematic however, when operational definitions are reduced to overly simple methodological descriptions that do not map sufficiently to rich concepts. When this happens, the chosen operations may encourage unwarranted inferences about those theoretical constructs. Researchers have struggled to operationalize dimensions of the religious and the spiritual that have more than one interpretation in addition to the more mundane features of human experience thought fundamental to social psychological research, such as personal identity (Hoare, 2012). The problems of operationalizing complex theoretical constructs that allow for replicable assessment have resulted in lack of consensus on best practices across social psychological research (Miller \& Thoresen, 2003). Together, these issues can detract from the validity and reliability of individual studies. If rich concepts cannot be adequately simulated, it can detract from the quality of experimental evidence in support of the theories elaborating those concepts.

Another concern is that some physical variables (e.g., length, weight) lend themselves to operationalization better than do psychological variables (Adams \& Miller, 2008; Slaney, 2001). If the operations we used to define karma do not map one-to-one to the details of the concept of karma, as elaborated in Buddhist texts, this may be a problem for our karma study. For example, our operational definition had to exclude elements of the theory such as rebirth and longer-term karmic effects. It is characteristic of the social psychological paradigm guiding our research that only the facets of constructs that are amenable to laboratory measurement are typically studied. As a result, both the complexity and variety of types of constructs may be underrepresented.

Despite the importance in psychology of the philosophical commitment to operationism, it is a topic rarely presented outside introductory texts, and even these presentations tend not to present its limitations (Costa \& Shimp, 2011). Costa and Shimp note that operationism is endorsed as a methodology in introductory psychology texts without making explicit the underlying commitment to a positivist philosophy of science. They attribute the general lack of discussion or criticism about the tenets of positivism (including operationism) among psychologists, to the discipline's ahistorical understanding of science, and the way that this ahistorical understanding implies that an analysis of psychology's relation to philosophy is unnecessary (p. 27). They argue that the positivist foundation of psychological science has been supported by appeals to logic and authority rather than empirical evidence. We agree with Costa and Shimp (2011) that philosophical commitments to positivism should be justified empirically, which means accepting or 
rejecting operationism, for example, based on a critical analysis of the practical consequences to our work that arise from maintaining that commitment. In the study under consideration the consequences of our operational definitions were (a) limitations in our ability to capture the full breadth of the construct (construct validity) and (b) difficulties in assessing the adequacy of our operational definitions. As we discuss below, we concluded that these were acceptable ramifications as long as we followed some other recommendations for practice that also resulted from our analysis.

Beyond operationism, other commitments that are paradigmatic in social psychological research can be drawn out through analysis of our results, and the decisions we made in response to some of the anomalous results. For example, participants who received a given paragraph prime chose the corresponding behavior in the PD game only $40 \%$ of the time, a rate attributable to chance. Our a priori requirement to consider the manipulation of pro-social behavior a success was for at least $90 \%$ of participants across conditions to make PD game decisions that corresponded to the behavior endorsed by the prime they received. Clearly, the prime did not have the anticipated effect on behavior, nor did it directly affect the cooperativeness ratings of the target. However, regardless of the priming condition, people who cooperated rated the target significantly more cooperative relative to people who competed $(t(36)=3.12, p<.01)$. As predicted, behavior affected ratings on cooperativeness-related traits only, not the average of the ratings of the positive, unrelated traits (truthful, amusing, affectionate; $t(13)=-.505, n s$ ) or neutral, unrelated traits (reserved, perfectionist, unpredictable; $t(30)=1.2, n s$ ).

In accordance with the paradigmatic commitments underlying hypothesis testing in social psychology, we used statistical analyses to rule out alternative explanations for these findings. We addressed the possibility that chronic beliefs about human nature and the trustworthiness of others would predict impression ratings, finding that the effect of these pre-existing beliefs were independent of the effect of cooperative behavior. This strengthened the case for an effect of behavior, or karma.

The paradigmatic commitments to hypothesis testing also required successful random assignment of the independent variable. This requirement guided our decisions about the methodology of a second experiment, in which we aimed for the priming manipulation to influence judgments (i.e., PD behavior) in a fashion consistent with past priming studies. The working assumption was that the paragraph priming manipulation was too weak in the first study, and that it was necessary to strengthen it by modifying the experimental design. We also hypothesized that participants were not fully grasping the nature of the dilemma presented in the payoff matrix of the PD game. To make the manipulation of behavior stronger, both the priming task and PD game were modified. The potential for the prime to activate the given construct was enhanced by adding "manipulation check" questions to assess participants' understanding of the paragraph. We added a corresponding recall task in which they were asked to relate an example of selfless or selfish behavior from their own past experience. Also, hypothetical research claiming to establish the benefits of selfless or selfish behavior was presented, along with manipulation check questions for comprehension. The PD payoff matrix was adjusted in the "golden rule" and "self-serving" conditions to make the corresponding behavior more appealing. When implemented in the second study, these modifications did produce the desired manipulation of behavior, as just over $85 \%$ of participants behaved according to the "philosophy of life" presented in the prime. 
Many alternative courses of action could have been pursued in response to the anomalous results of the first study, but were pre-empted by the guiding commitments of our paradigm(s). Failure of the behavior manipulation could have been interpreted as evidence falsifying the scientific prediction for priming effects. This would have entailed questioning the scientists and experiments after which the karma study was modeled. This course was not pursued because of our rational, that is, empirically well-supported, commitment to the view that established findings for priming effects should continue to generalize to new situations, priming tasks, outcome measures, groups of individuals, naturalistic settings, and the conditions of one's own laboratory. We attributed the failure of the manipulation to the method, not our operationalization of the construct, and when the anticipated result was not shown in our first data set, there were two explanatory options: either (a) the proposed relationship between the variables was not captured in the study due, for example, to an inadequate methodology resulting in too much noise or (b) the study's method was adequate but did not reflect the proposed relationship between the variables because that relationship does not exist. Only the second option allows for falsification of a hypothesis; the first calls for tighter methodological control. Severity of hypothesis testing in experimental social psychology is a function of the scientist's level of control over variables, which is, unfortunately, directly related to the artificiality of the social environment under observation. ${ }^{7}$

One recourse for scientists facing anomalous results is to explore, through more experiments, the specific conditions under which the (anomalous) effect holds. The more moderators that are identified, the more accurate a theory will be in making predictions - but this comes at the expense of parsimony. Thorngate (1976) suggested that there is a continuum between simply describing a phenomenon, which entails no generalizability, but can be as accurate as one has the patience for, and establishing general laws that are widely applicable but (generally) provide for far less accurate descriptions of realized events or cases. Establishing infinitely more limitations to the applicability of a law of behavior tends toward a description that is limited by historical, temporal, and cultural context. If one believes that general laws can and should be established for social sciences, as they often are for other sciences, then "mere" practices of description in psychology will be viewed as inadequate (see Gergen, 1973 and Schlenker, 1974 for two sides of this debate). Of course, social psychologists can also take comfort in knowing that the establishment of, need for, and epistemic implications of general laws in other sciences are also debated (see, for example, Cartwright, 1999; Dupre, 1993).

Having outlined the advantages and disadvantages of the guiding philosophical/theoretical commitments we now try more carefully to assess their consequences. These commitments have functioned well in certain situations, such as the initial studies of the fundamental attribution error (Jones et al., 1972), revealing what are now almost universally observable tendencies in person perception. Jones et al.'s original study, in which participants rated the attitudes of others who wrote pro- or anti-Fidel Castro essays, captured the bias toward dispositional attribution. Subsequent Kuhnian puzzle solving resulted in establishing a widely observed law-like tool for predicting how people explain the behavior of others. However, if puzzle solving instead produces anomalous results, as in the first round of our karma study (or any number of other studies that have examined equally complex social phenomena without replicating previous findings), then 
these paradigmatic commitments can inappropriately encourage the pursuit of different experimental methods. Such encouragement is inappropriate if the anomalous results were caused not by methodological decisions per se, but by commitment to operational definitions that do not thoroughly capture the theoretical constructs in question.

No single study, making use of a limited set of operations, in one setting, tested on one population, could be expected to capture complex social phenomena thoroughly enough to allow for generalizability and application (Shadish, Cook, \& Campbell, 2002). Fortunately, a single study is not the unit by which scientific knowledge is established. Rather, the process of demonstrating the generalizability of causal inferences occurs across numerous studies and disciplines. However, in social psychology, in the face of anomalous results, the question remains whether tighter control in the lab (better methods) is warranted. It may be difficult to determine whether the initial methods were based on, for example, fundamentally inadequate operational definitions without pursuing follow-up studies that generalize across operational definitions, provide richer theoretical resources, and increase construct validity. Additionally, it can be difficult to assess the adequacy of operational definitions, given that the follow-up studies used to increase generalizability tend only to be justified by initial studies that yield significant (and often non-anomalous) findings. If significant results are not forthcoming, the study seldom sees publication (the "file drawer problem"). The file drawer problem can also account for known limitations of operational definitions being underrepresented in the literature. Finally, anomalous results may not be as anomalous as they seem because we typically can only judge our own results against a body of published evidence biased toward statistically significant results.

This assessment of the practical consequences of our philosophical/theoretical commitments has encouraged us to uphold some of our original choices around the design of the first and second study, alerted us to commitments that deserve continued critical attention in the future, and prompted us to think about how to incorporate those criticisms into our practice. Despite the limitations discussed, the assumptions around the adequacy of our operational definition and pursuit of better methods seem worth upholding considering evidence that our basic research question is important enough to be motivating a variety of studies that use a variety of measurements for capturing karma-like phenomena (Allen, Edwards, \& McCullough, 2014). This context gives us good reason to think that the results of our single study are more likely than they would otherwise be to contribute toward the body of studies that will, together, advance knowledge in this area. We found little reason to continue support for the paradigmatic assumption guiding the exclusive publication of significant results. A practical payoff resulting from that part of our analysis is our prescription that psychologists adapt our research process in a way that builds in critical attention to the issue. In the future we would devote more attention to a variety of sources informing the design and conceptualization stages of a study. This practice would be aided by better access to and funding for repositories for study results (regardless of the significance of the findings) created by funding agencies or professional organizations that could then be weighted in the formulation of questions worth asking, hypothesized results, and operational definitions.

As our recounting of the karma study illustrates, researchers faced with anomalous results have to rely heavily on existing empirical evidence from past studies to determine 
whether pursuit of better methods is justified. We suggest that in the course of pursuing increasingly better methods, researchers should be encouraged to think critically about what sorts of empirical evidence (if any) support this pursuit, and which might involve thinking critically about the paradigmatic commitments that drive the pursuit. Additionally, as tighter control in the lab and investigation of potential moderators leads to artificiality and increasingly descriptive (as opposed to generalizable) results, researchers must re-examine whether the pursuit will yield accurate descriptions of social phenomena at the expense of providing answers to interesting and compelling research questions. Properly conceived as empirical through and through, the investigation of philosophical/theoretical commitments could play a larger role at this decision point, especially in determining whether subsequent research questions under tighter control continue to be relevant, important, and worth asking.

\section{Conclusion}

In contrast to Henley (1989) we believe that, insofar as Meehl's (1978) paper failed to get the requisite uptake in social psychology, this can best be explained by a more general failure within social psychology (even still) to reward adequately the critical discussion of philosophical/theoretical commitments that guide research. And of course we believe that these critical discussions are only possible with an adequate understanding of what these commitments are and how they are formed. While the field of theoretical psychology has produced a number of critical discussions of the philosophical/theoretical commitments underlying contemporary psychological research, some influential essays make use of problematic interpretations of Kuhn to characterize these commitments as nonempirical, and irrational (e.g., Gergen,1985; Manicas \& Secord, 1983). In contrast, we make use of a pragmatist account to show that and how these commitments can be articulated in terms of empirical evidence, broadly construed. Our account also better explains how any of the critical discussions referred to above can actually take place. As long as the philosophical/theoretical commitments underlying psychological research are seen as nonempirical and irrational - as long as investigations of those commitments are seen as distractions from the proper empirical focus of psychological research - then the important ongoing and historical role of these commitments will be trivialized, and those whose work involves examining these commitments will be marginalized.

We modeled a rational critical analysis of philosophical/theoretical commitments in our discussion of a recent study in the social psychology of religion. We argued that the commitments at work in this study are paradigmatic in the sense that they are typically taken for granted, entrenched, and formally organized in social psychological research in the northern/western academic context. However, while these commitments are ubiquitous and largely implicit, they are beliefs that have empirical content or are semantically linked to beliefs that do; and as such, their empirical consequences can be rationally evaluated, even if not experimentally tested. In other words, while these commitments run deep, they are not immune to critical analysis. Theoretical psychologists are wellplaced to make these analyses. What is needed is for such analyses to be understood as continuous with empirical investigations, to be discussed early in social psychological pedagogy, and for the discussions to be rewarded and encouraged. 


\section{Acknowledgements}

We thank Hank Stam and two anonymous reviewers for their editorial guidance; John Edwards for valuable contributions in the development and implementation of the original karma experiments discussed in this paper, and Winston McCullough for his analysis of Buddhist views of karma. We also thank Jonathan Kaplan, Sione Filimoehala, Matthew Gaddis, and Sean Creighton for their helpful comments on earlier drafts of this paper.

\section{Funding}

This research received no specific grant from any funding agency in the public, commercial, or not-for-profit sectors.

\section{Notes}

1. In this paper, we do not address the view that there is nothing rational to be said or assessed about empirical beliefs generally, instead we assume that there is and expand the set of empirical beliefs to include philosophical/theoretical commitments.

2. See also Machamer and Osbeck (2003) for a discussion of some of the rhetorical complexities of this essay.

3. Within the theoretical psychology literature, see for example, Henley (1989), Morgan, (2007), van Haaften (2007); and within philosophy, see Bird (2000) and Sankey (1993).

4. Our discussion of karma is based on a recent review by Allen et al. (2014).

5. See Wallach and Wallach (1994) for a good discussion of the ubiquity of this problem.

6. See Bickhard (1992) for a compelling discussion of the "vestigial" role of positivism in psychology.

7. Having already mentioned Meehl's (1978) paper we should acknowledge, and indeed support his concern with the paradigmatic commitment to null hypothesis testing in psychology, in particular his argument that the null hypothesis is likely to be false, as a matter of course, so comparing results to the null is not setting a high enough standard of falsification. Leaving aside his positions on Popper, we appreciate Meehl's suggestion that psychologists move away from significance testing and towards triangulation between and consistency with results from different experimental set-ups. And for this, theoretically rich operational definitions will be important so researchers can know if and when they are converging on the same result from two or more different kinds of approaches.

\section{References}

Adams, J. B., \& Miller, R. B. (2008). Bridging psychology's scientist vs. practitioner divide: Fruits of a twenty-five year dialogue. Journal of Theoretical and Philosophical Psychology, 28, 375-394. doi: 10.1037/h0092064

Allen, P. M., Edwards, J. A., \& McCullough, W. (2014). Does karma exist?: Buddhism, social cognition and the evidence for karma. International Journal for the Psychology of Religion, 25, 1-17. doi: 10.1080/10508619.2013.879427

Anderson, E. (2004). The uses of value judgments in science. Hypatia, 19, 1-24. doi: 10.1353/ hyp. 2004.0002

Bargh, J. A., Bond, R. N., Lombardi, W. J., \& Tota, M. E. (1986). The additive nature of chronic and temporary sources of construct accessibility. Journal of Personality and Social Psychology, 50, 869-878. doi: 10.1037/0022-3514.50.5.869

Barker, P., Chen, X., \& Andersen, H. (2003). Kuhn on concepts and categorization. In T. Nickles (Ed.), Thomas Kuhn (pp. 212-245). Cambridge, UK: Cambridge University Press. 
Bickhard, M. H. (1992). Myths of science: Misconceptions of science in contemporary psychology. Theory \& Psychology, 2, 321-337. doi: 10.1177/0959354392023004

Bird, A. (2000). Thomas Kuhn. Rutgers, NJ: Princeton University Press.

Brinkmann, S. (2008). Culture as practices: A pragmatist conception. Journal of Theoretical and Philosophical Psychology, 28, 192-212. doi: 10.1037/h0091293

Brinkmann, S. (2011). Dewey's neglected psychology: Rediscovering his transactional approach. Theory \& Psychology, 21, 298-317. doi: 10.1177/0959354310376123

Bruner, J. (1957). On perceptual readiness. Psychological Review, 64, 123-152. doi: 10.1037/ h0043805

Cartwright, N. (1999). The dappled world: A study of the boundaries of science. Cambridge, UK: Cambridge University Press.

Clough, S. (2003). Beyond epistemology: A pragmatist approach to feminist science studies. Lanham, MD: Rowman and Littlefield.

Clough, S. (2008). Solomon's empirical/non-empirical distinction and the proper place of values in science. Perspectives in Science, 16, 265-279. doi: 10.1162/posc.2008.16.3.265

Clough, S. (2011). Radical interpretation, feminism, and science. In J. Malpas (Ed.), Dialogues with Davidson (pp. 405-426). Boston, MA: MIT Press.

Costa, R. E., \& Shimp, C. P. (2011). Methods courses and texts in psychology: "Textbook science" and "tourist brochures." Journal of Theoretical and Philosophical Psychology, 31, 25-43. doi: $10.1037 / \mathrm{a} 0021575$

Cronbach, L. J., \& Meehl, P. E. (1955). Construct validity in psychological tests. Psychological Bulletin, 52, 281-302. doi: 10.1037/h0040957

Dargyay, L. (1986). Tsong-Kha-Pa's concept of karma. In R. W. Neufeldt (Ed.), Karma and rebirth: Post classical developments (pp. 169-178). New York: State University of New York Press.

Davidson, D. (1984). On the very idea of a conceptual scheme. In Inquiries into truth and interpretation (pp. 183-198). Oxford, UK: Clarendon Press. (Original work published 1974)

Davidson, D. (1989). The myth of the subjective. In M. Krausz (Ed.), Relativism: Interpretations and confrontations (pp. 159-172). Bloomington: Indiana University Press.

Davidson, D. (2004). The problem of objectivity. In Problems of rationality (pp. 3-18). Oxford, UK: Clarendon Press. (Original work published 1995)

De Silva, P. (1990). Buddhist psychology: A review of theory and practice. Current Psychology, 9, 236-254. doi: 10.1007/BF02686862

Dewey, J. (1916). Democracy and education: An introduction to the philosophy of education. New York, NY: Macmillan.

Dewey, J. (1929). The quest for certainty. New York, NY: Minton, Balch, and Co.

Dupre, J. (1993). The disorder of things: Metaphysical foundations of the disunity of science. Cambridge, MA: Harvard University Press.

Feyerabend, P. (1975). Against method. Scranton, PA: Verso.

Gergen, K. J. (1973). Social psychology as history. Journal of Personality and Social Psychology, 26, 309-320. doi: 10.1037/h0034436

Gergen, K. J. (1985). The social constructionist movement in modern psychology. American Psychologist, 40, 266-275. doi: 10.1037/0003-066X.40.3.266

Henley, T. B. (1989). Meehl revisited: A look at paradigms in psychology. Theoretical and Philosophical Psychology, 9, 30-36. doi: 10.1037/h0091459

Hoare, C. (2012). Three missing dimensions in contemporary studies of identity: The unconscious, negative attributes, and society. Journal of Theoretical and Philosophical Psychology, 33, 1-17. doi: $10.1037 / \mathrm{a} 0026546$ 
Jones, E. E., Kanouse, D. E., Kelley, H. H., Nisbett, R. E., Valins, S., \& Weiner, B. (1972). Attribution: Perceiving the causes of behavior. Morristown, NJ: General Learning Press.

Koch, S. (1992). Psychology's Bridgman vs Bridgman's Bridgman. Theory \& Psychology, 2, 261-290. doi: 10.1177/0959354392023002

Kuhn, T. S. (1970). Logic of discovery or psychology of research? In I. Lakatos \& A. Musgrave (Eds.), Criticism and the growth of knowledge (pp. 1-23). New York, NY: Cambridge University Press.

Kuhn, T. S. (1977). Objectivity, value judgment, and theory choice. In The essential tension: Selected studies in the scientific tradition and change (pp. 320-339). Chicago, IL: University of Chicago Press.

Kuhn, T. S. (1996). The structure of scientific revolutions (3rd ed.). Chicago, IL: University of Chicago Press. (Original work published 1962)

MacCorquodale, K., \& Meehl, P. E. (1948). On a distinction between hypothetical constructs and intervening variables. Psychological Review, 55, 95-107. doi: 10.1037/h0056029

Machamer, P., \& Osbeck, L. (2003). Scientific normativity as non-epistemic: A hidden Kuhnian legacy. Social Epistemology, 17, 3-11. doi: 10.1080/0269112032000114804

Manicas, P. T., \& Secord, P. F. (1983). Implications for psychology of the new philosophy of science. American Psychologist, 38, 399-413. doi: 10.1037/0003-066X.38.4.399

Martin, J. (2003). Positivism, quantification, and the phenomena of psychology. Theory \& Psychology, 13, 33-38. doi: 10.1177/0959354303013001760

Mayo, D. (1996). Error and the growth of experimental knowledge. Chicago, IL: University of Chicago Press.

Meehl, P. E. (1978). Theoretical risks and tabular asterisks: Sir Karl, Sir Ronald, and the slow progress of soft psychology. Journal of Consulting and Clinical Psychology, 46, 806-834. doi: 10.1037/0022-006X.46.4.806

Miller, W. R., \& Thoresen, C. E. (2003). Spirituality, religion, and health: An emerging research field. American Psychologist, 58, 24-35. doi: 10.1037/0003-066X.58.1.24

Morgan, D. L. (2007). Paradigms lost and pragmatism regained: Methodological implications of combining qualitative and quantitative methods. Journal of Mixed Methods Research, 1, 48-76. doi: 10.1177/2345678906292462

Osbeck, L. M. (2005). Method and theoretical psychology. Theory \& Psychology, 15, 5-26. doi: $10.1177 / 0959354305049742$

Quine, W. V. O. (1960). Word and object. Cambridge, MA: MIT Press.

Rogers, T. B. (1989). Operationism in psychology: A discussion of contextual antecedents and an historical interpretation of its longevity. Journal of the History of the Behavioral Sciences, 25, 139-153. doi: 10.1002/1520-6696(198904)25:2<139::AID-JHBS2300250204>3.0.CO;2-E

Sankey, H. (1993). Kuhn's changing concept of incommensurability. British Journal of the Philosophy of Science, 44, 759-774. doi: 10.1093/bjps/44.4.759

Sarason, S. B. (1984). If it can be studied or developed, should it be? American Psychologist, 39, 477-485. doi: 10.1037/0003-066X.39.5.477

Schlenker, B. R. (1974). Social psychology and science. Journal of Personality and Social Psychology, 29, 1-15. doi: 10.1037/h0035668

Shadish, W., Cook, T. D., \& Campbell, D. T. (2002). Experimental and quasi-experimental designs for generalized causal inference. Belmont, CA: Wadsworth Cengage Learning.

Slaney, K. L. (2001). On empirical realism and the defining of theoretical terms. Journal of Theoretical and Philosophical Psychology, 21, 132-152. doi: 10.1037/h0091202

Stam, H. J. (2001). Introduction: Varieties of social constructionism and the rituals of critique. Theory \& Psychology, 12, 571-576. doi: 10.1177/0959354302012005893 
Sternberg, R. J., Grigorenko, E. L., \& Kalmar, D. A. (2001). The role of theory in unified psychology. Journal of Theoretical and Philosophical Psychology, 21, 99-117. doi: 10.1037/ h0091200

Sugarman, J. (1995). Transcendental interpretation: An alternative approach to psychological inquiry. Journal of Theoretical and Philosophical Psychology, 15, 16-40. doi: 10.1037/h0091145

Thorngate, W.(1976). "In general" vs. "it depends": Some comments on the Gergen-Schlenker debate. Personality and Social Psychology Bulletin, 2, 404-410. doi: 10.1177/014616727600200413

Tsongkhapa. (2000). The great treatise on the stages of the path to enlightenment. (Lamrim Chenmo Translation Committee, Trans., Vol. 3). Ithaca, NY: Snow Lion.

Vandenberg, B. R. (2010). Evidence, ontology, and psychological science: The lesson of hypnosis. Journal of Theoretical and Philosophical Psychology, 30, 51-65. doi: 10.1037/a0016665

van Haaften, W. (2007). Conceptual change and paradigm change: What's the difference? Theory \& Psychology 17, 59-85. doi: 10.1177/0959354306070531

Wallach, L., \& Wallach, M. A. (1994). Gergen versus the mainstream: Are hypotheses in social psychology subject to empirical test? Journal of Personality and Social Psychology, 67, 233242. doi: 10.1037/0022-3514.67.2.233

Wertheimer, M. (1986). The implicit assumptions of modern psychology. Journal of Theoretical and Philosophical Psychology, 6, 5-17. doi: 10.1037/h0091410

Wittgenstein, L. (2001). Philosophical investigations. New York, NY: Blackwell. (Original work published 1953)

\section{Author biographies}

Pamela M. Allen is a doctoral candidate in Human Development and Family Studies and a graduate fellow in the National Science Foundation Integrative Graduate Education and Research Training (IGERT) in Aging Sciences program at Oregon State University. Her research interests center around ageism and healthy aging with a focus on health behavior and the processes by which perceptions of aging shape goals, health, and psychological well-being. She has examined aging stereotypes cross-culturally, and has also published in the areas of psychology of religion and judgment and decision-making. Email: allenpa@onid.oregonstate.edu.

Sharyn Clough is an associate professor of Philosophy at Oregon State University. Specializing in the philosophy of science, especially biomedicine, she uses a contemporary pragmatist approach to investigate the role of values in scientific practice. She is the author of Beyond Epistemology: A Pragmatist Approach to Feminist Science Studies (2003), and the editor of Siblings Under the Skin: Feminism, Social Justice, and Analytic Philosophy (2003). In addition, she has written a number of essays on science and values for journals such as Social Science and Medicine, Studies in the History and Philosophy of the Biological and Biomedical Sciences, Metascience, Perspectives in Science, and Journal of Social Philosophy. Email: sharyn.clough@oregonstate.edu. 